\title{
Prevalence and predictors of overweight and obesity among school-aged children in urban Ghana
}

\author{
Richmond Aryeetey ${ }^{1 *}$, Anna Lartey ${ }^{2}$, Grace S. Marquis ${ }^{3}$, Helena Nti ${ }^{2}$, Esi Colecraft ${ }^{2}$ and Patricia Brown ${ }^{4}$
}

\begin{abstract}
Background: Childhood overnutrition is a serious public health problem, with consequences that extend into adulthood. The aim of this study was to determine the prevalence and determinants of overweight and obesity among school-age children in two urban settings in Ghana.

Methods: This cross-sectional study involved 3089 children (9-15 years) recruited between December 2009 and February 2012 in Accra and Kumasi, Ghana. Socio-demographic, dietary, and physical activity data were collected using pretested questionnaires. BMl-for-age z-scores were used to categorize anthropometric data of the children as thin, normal, or overweight/obese. Determinants of overweight were examined using multiple logistic regressions.

Results: Seventeen percent of children were overweight or obese. Children who reported lower participation ( $<3$ times/week) in sports activity were $44 \%$ more likely to be overweight or obese (AOR $=1.44 ; 95 \% \mathrm{Cl}: 1.07$, 1.94). Maternal tertiary education ( $A O R=1.91,95 \% \mathrm{Cl}: 1.07,3.42$ ), higher household socioeconomic status ( $\mathrm{AOR}=1$. $56,95 \% \mathrm{Cl}: 1.18,2.06)$, and attending private school $(A O R=1.74,95 \% \mathrm{Cl}: 1.31,2.32)$ were also associated with elevated risk of overweight and obesity.

Conclusions: Physical inactivity is a modifiable independent determinant of overweight or obesity among Ghanaian school-aged children. Promoting and supporting a physically active lifestyle in this population is likely to reduce risk of childhood overnutrition.
\end{abstract}

Keywords: School-age children, Overweight, Obesity, Physical activity, Urban, Ghana

\section{Background}

Childhood overweight and obesity is a serious public health challenge affecting both developed and developing countries [1]. The prevalence of overweight and obesity is increasing rapidly in developing countries; in some countries, high rates of childhood overweight (> 15\%) have been reported [2]. The current increasing prevalence of overweight has been partly attributed to the nutrition transition which is characterised by systemic societal changes such as increased urbanization, industrialization, trade liberalization, and economic growth. All these changes influence the food system in ways that then fuel behavior changes linked with increased energy-dense food consumption and reduced

\footnotetext{
* Correspondence: raryeetey@ug.edu.gh

'School of Public Health, University of Ghana, Box LG 13 Legon, Accra, Ghana Full list of author information is available at the end of the article
}

physical activity $[3,4]$. In particular, living in an urban setting has been linked with increased risk of childhood obesity in developing countries $[2,5]$.

One suggested pathway through which urbanization influences overnutrition is by reducing opportunities for physical activity [6]. The reported mechanisms of this relationship include increased access to and use of motorized transport $[7,8]$ as well as computerized devices which displace time which would otherwise be used for activity $[9,10]$. Simultaneously, urban-dwelling children do not consume adequate amounts of fruits and vegetables, and also have more access to energy-dense foods high in fat, sugar and salt, including out-of-home, readyto-eat meals and snacks [11]. In urban Benin, out-ofhome prepared foods contributed more than $40 \%$ of the daily energy intake of school-going adolescents; those who consumed more than $55 \%$ of energy out of home 
ate more sweetened energy-dense foods, and less fruits and vegetables compared to those who consumed less out of home ( $<34 \%$ of energy) [12].

Childhood and adolescent overweight and obesity are associated with both short- and long-term adverse effects related to health and development. In the short term, obese young adolescents have an elevated risk of low self-esteem, negative self-image, hyperlipidemia, elevated blood pressure, and hyperinsulinemia compared to non-obese children $[13,14]$. In addition, overweight in early childhood is likely to persist into adulthood, and thereby further increase risk of overweight-related chronic disease sequelae in adulthood [15]; this relationship is particularly stronger among older children (>10 years) $[16,17]$. Thus, childhood overweight is associated with adverse effects on adult outcomes resulting in an unhealthy workforce, increased cost of health care, and limiting total population productivity. It is therefore important that strategies to address overweight and obesity start among children and adolescents. A critical step towards addressing overweight is a better understanding of the scope of the problem, as well as associated factors.

In Ghana, information on childhood obesity is scarce, particularly for children of school age. The 2007 Global School-based Student Health Survey reported overweight and obesity prevalence of $7 \%$ among Ghanaian children 13-15 years [18]. This survey is, however, limited by its use of self-reported anthropometric data among both rural and urban school-going children. There is thus a gap in knowledge on the magnitude and determinants of overweight and obesity among schoolgoing children that is based on a representative sample of the urban population. Identifying risk factors of overnutrition among children and adolescents will provide the basis for comprehensive interventions to address obesity. Therefore, the main objective of this study was to determine the prevalence and risk factors of overweight and obesity among 9-15 year old school-age children in two urban settings of Accra and Kumasi in Ghana. The study will also explore the key risk factors of overweight and obesity among school-age children in Ghana.

\section{Methods}

\section{Study population}

This was a cross-sectional survey involving 3089 schoolage children between the ages of 9 and 15 years who were recruited from 121 schools located in the two largest urban centres of Ghana: Accra (the capital city of Ghana) and Kumasi (Fig. 1). Children in the 9-15 years age group were recruited from either upper primary level or junior high school level. This age group was selected for two main reasons: 1) under-representation in nation-wide surveys, and 2) it is a target of on-going school nutrition interventions in the Ghanaian context. The schools included in the study were either exclusively primary, exclusively junior high, or having both primary and junior high level children together in a single school. The study was implemented between December 2009 and February 2012.

The study was approved by the Ethical Review Boards of McGill University (A09-B21-09A), Canada and the Noguchi Memorial Institute for Medical Research (004/ 09-10), University of Ghana, Legon. Prior to data collection, administrative permissions were also obtained from the national office of the Ghana Education Service as well as from head teachers of all participating schools. Written informed consent was obtained from all parents whose children participated in the study. In addition, each participating child provided signed assent before the questionnaire was administered.

\section{Sampling}

Due to expected higher prevalence of overweight and obesity among children attending private schools in Ghana, sample sizes were estimated separately for public and private schools. In public schools, the estimated sample was 954; in private schools, the estimate was 1808. These estimates were based on an overweight prevalence of $10 \%$ in private schools and $5 \%$ in public schools, a margin of error of $1.5 \%$, and a $95 \%$ confidence interval, and allowing for $15 \%$ loss due to incomplete data. Using a cluster sampling plan, 57 public schools that had both primary and junior high school (JHS) departments were randomly selected. Assuming 20\% parental refusal, a total of 20 pupils (10 males and 10 females) were randomly selected and contacted in each school. Using a similar cluster sampling for the private schools, 64 private primary and junior secondary schools were randomly selected. In each school, 36 pupils (18 females and 18 males) were randomly selected and contacted.

\section{Data collection}

Questionnaires were administered to the school children, individually. Data collected with the questionnaire included socio-demographic characteristics, dietary habits, physical activity, and television viewing. Each child and parent had the weight and height measurements taken and recorded by a trained research assistant. The measurements were taken at the school premises.

\section{Socio-demographic data}

A structured pre-tested questionnaire was used to collect information on household demographic and socioeconomic characteristics including educational, home 


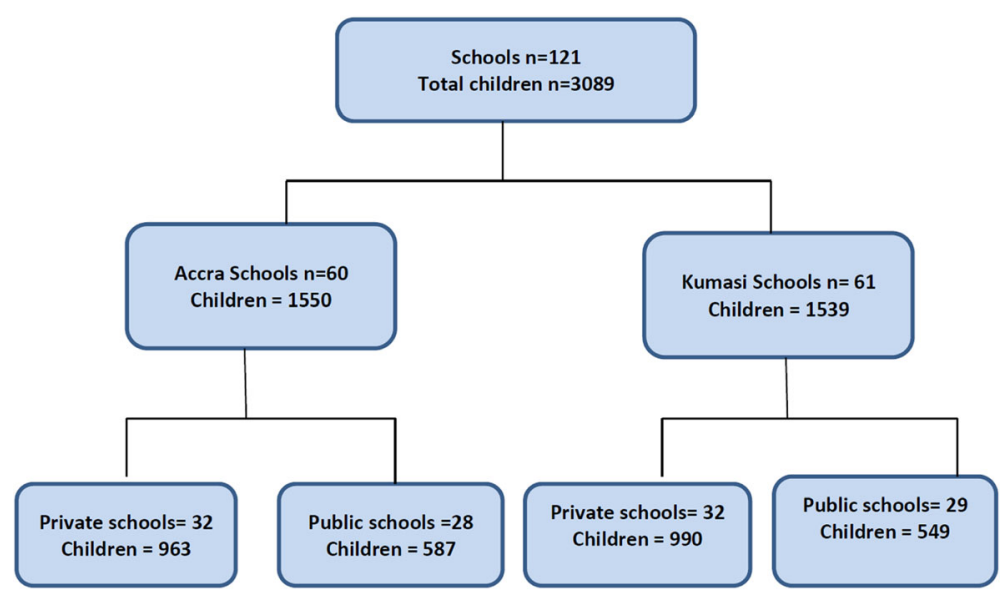

Fig. 1 Diagram showing flow of school children in the study

living arrangements, and occupation of parents. In addition, ownership of household assets, including refrigerator and television, video player, and automobile were documented. This information was obtained from the children with the assistance of parents (where a parent was available).

\section{Dietary and physical activity assessment}

Dietary intakes of the school children were assessed using a food frequency questionnaire that had a reference period of one week prior to the survey. The questionnaire consisted of 60 food items and focused on describing patterns of consumption of high fat foods, high sugar foods, sweetened drinks, fruits, and vegetables. The frequencies of intake of the listed foods over time (daily and weekly) by the school children were then determined. The food frequency questionnaire was designed for this study by identifying commonly consumed foods in Ghana under each of 11 food groups. The food groups were sugar-sweetened beverages, milk and dairy products, cereal products (including breads and biscuits), fried foods, animal-source foods, spreads and toppings, fruits, vegetables, soups, sweets and high calorie foods, and other staple foods. An initial list of foods was pre-tested among mothers in Accra, following which additional foods were added. During the survey, opportunity was provided for including additional foods that were reportedly consumed. A pretested questionnaire was used to collect information on the level of physical activity and sports participation of study children. The specific questions included the frequency and duration of television viewing, number of days per week child walked to school, and frequency of performing house chores and participation in sporting and other physical activities including football, ampe (indigenous Ghanaian jumping game), hockey, table tennis, lawn tennis, rope skipping, volleyball, basketball, swimming and gardening.

\section{Anthropometry}

All anthropometric measurements were carried out at the school premises. Participants removed all heavy clothing and accessories (such as shoes or sandals, belts, watches, and sweaters) and emptied their pockets (where necessary), prior to the measurement. Body weight was measured to the nearest $0.1 \mathrm{~kg}$ using the Tanita Digital Scale (model BWB-800, Tanita Corporation, USA). Height measurements were taken to the nearest $0.1 \mathrm{~cm}$ using the Shorr Board (Shorr Productions, Olney, MD). Parents were invited to the school for weight and height to be taken. All measurements were done and recorded in duplicate. Weight and height measurements were converted to body mass index for age z-scores (BMIZ) based on the WHO Child Growth Standards [19]. Overweight was defined as BMIZ greater than one standard deviation from the median; obesity was determined as BMIZ greater than two standard deviations [20].

\section{Statistical analyses}

Two factors were created from a set of seven socioeconomic status (SES) variables using factor analysis with varimax rotation as proxy indicators for household socio-economic status. The first factor reflected household items such as television and refrigerator and the second reflected occupation and ownership of items such as home, air conditioner, and vehicle. Tertiles of the factors are reported. Regarding dietary data, proportions were reported for how frequently dietary behaviors and foods with established links to obesity were reported by respondents. Analyses were carried using cases with complete data. The proportion of children who were overweight or obese (BMIZ >1 SD) was computed. Multiple logistic regression procedure was used to examine characteristics that were statistically and independently associated with overweight or obese status. The factors considered were those that were shown to 
be either significantly correlated $(p<0.05)$ or tended to be correlated $(p<0.10)$ with overweight and obesity, and included child characteristics (age, sex, dietary habits, physical activity, type of school), maternal characteristics (education, occupation), and household characteristics (household wealth status). The region of residence and correlation within clusters (school) were controlled for in the model. The final model included only factors that were associated with overweight or obesity at $p<0.05$. We used weights in the analysis to restore the representativeness of the sample. All statistical analyses were conducted using SAS (version 9.2, Cary, NC, USA) and statistical significance in the final model was determined at $p<0.05$.

\section{Results}

The current analysis included 3089 out of the 3444 school children who were sampled (Fig. 1). The majority $(90 \%)$ of children who were sampled but not included did not show up on the day of data collection; the remainder either refused participation $(9 \%)$ or were ineligible because of their age (1\%). The mean age of children who participated in the study was $12.2 \pm$ 1.7 years and more than half of them were female (Table 1). Most of the children ate breakfast during the school week, with $85 \%$ having breakfast more than three days per week (Table 2). Consumption of fruits and vegetables was low. Only $20 \%$ and $38 \%$ had consumed fruits and vegetables $>5$ times, respectively, the previous week. About three-quarters of the children $(76 \%)$ walked to school at least four out of the five school days in a week and more than half (58\%) did household chores during the week. However, involvement in sporting activities was low, with less than one-third of the children engaging in a sport at least three times in a week. Television watching was also low among the study sample. Less than $15 \%$ watched television at least five times during the week prior to the survey. The overall prevalence of overweight and obesity was 14.7\% among the children, with $4.4 \%$ being obese (Table 3 ). A higher proportion of children were overweight (including obese) in the private compared to the public schools $(21.4 \%$ vs $11.2 \%, p<0.001)$.

\section{Risk factors of overweight and obesity}

Table 4 shows the factors that were significantly associated with being overweight or obese in the study sample, based on multiple logistic regression. Female children were twice as likely to be overweight or obese compared to male children (AOR $=2.38,95 \% \mathrm{CI}: 1.79,3.18)$. None of the dietary habits that were assessed was significantly associated the risk of overweight or obesity. Physical activity was a determinant of overnutrition among the children. Children who engaged in sports for less than
Table 1 Background characteristics of Ghanaian children 9-15 years

\begin{tabular}{|c|c|c|c|c|c|c|}
\hline & \multicolumn{2}{|l|}{ Total } & \multicolumn{2}{|c|}{ Private School } & \multicolumn{2}{|c|}{ Public School } \\
\hline & $\bar{n}$ & $\%$ & $\bar{n}$ & $\%$ & $\bar{n}$ & $\%$ \\
\hline \multicolumn{7}{|l|}{ Child's sex } \\
\hline Male & 1413 & 46.6 & 925 & 51.1 & 488 & 46.7 \\
\hline Female & 1617 & 53.4 & 1028 & 48.9 & 648 & 53.3 \\
\hline \multicolumn{7}{|l|}{ Maternal education } \\
\hline None & 174 & 56 & 74 & 3.8 & 100 & 8.8 \\
\hline Primary & 1055 & 34.2 & 558 & 28.0 & 497 & 43.5 \\
\hline Secondary (JHS/SHS) & 637 & 20.7 & 458 & 23.3 & 179 & 15.7 \\
\hline Tertiary & 357 & 11.6 & 287 & 14.8 & 70 & 6.1 \\
\hline Do not know & 860 & 27.9 & 572 & 30.1 & 288 & 25.9 \\
\hline \multicolumn{7}{|l|}{ Maternal occupation } \\
\hline Artisan & 515 & 16.7 & 302 & 15.5 & 213 & 18.8 \\
\hline Professional $^{a}$ & 380 & 12.3 & 302 & 15.5 & 78 & 6.7 \\
\hline Office worker ${ }^{b}$ & 71 & 2.3 & 52 & 2.6 & 19 & 1.7 \\
\hline Trading & 1884 & 61.0 & 1140 & 58.4 & 744 & 65.5 \\
\hline Not employed & 195 & 6.3 & 126 & 6.4 & 69 & 6.2 \\
\hline Do not know & 44 & 1.4 & 31 & 1.6 & 13 & 1.1 \\
\hline \multicolumn{7}{|l|}{ Household size } \\
\hline$\leq 3$ & 309 & 10.0 & 200 & 10.2 & 109 & 9.5 \\
\hline $4-6$ & 1785 & 57.8 & 1121 & 57.7 & 664 & 58.8 \\
\hline $7-9$ & 810 & 26.2 & 505 & 25.7 & 305 & 26.6 \\
\hline$\geq 10$ & 185 & 6.0 & 127 & 6.4 & 58 & 5.1 \\
\hline \multicolumn{7}{|c|}{ Household socioeconomic status factor $1^{c}$} \\
\hline Low & 1027 & 33.7 & 575 & 30.0 & 451 & 40.3 \\
\hline Medium & 981 & 32.2 & 725 & 37.7 & 256 & 22.6 \\
\hline High & 1037 & 34.1 & 621 & 32.3 & 416 & 37.1 \\
\hline \multicolumn{7}{|c|}{ Household socioeconomic status factor $2^{\mathrm{d}}$} \\
\hline Low & 1199 & 39.4 & 603 & 31.3 & 596 & 53.3 \\
\hline Medium & 825 & 27.1 & 501 & 26.1 & 324 & 28.9 \\
\hline High & 1021 & 33.5 & 818 & 42.6 & 203 & 17.7 \\
\hline
\end{tabular}

Values presented as number (percentage of private or public)

${ }^{a}$ Includes teachers, lawyers, doctors, and accountants

${ }^{b}$ Includes secretaries and office clerks

'Reflects possession of household items such as television, video player, and refrigerator

${ }^{d}$ Reflects occupation and ownership of assets such as home, air conditioner, and vehicle

three times a week were at a $44 \%$ higher odds of being overweight or obese when compared to those who were involved in sporting activities at least three times a week. High maternal education and household SES were risk factors for overweight and obesity. Children of mothers who received formal education beyond the secondary level were more likely to be overweight or obese compared to those whose mothers had no education (AOR $=1.91,95 \%$ CI: 1.07, 3.42). However, being educated up to the secondary level was not linked with overweight. Children living in households in the third SES tertile had 
Table 2 Dietary and physical activity habits of Ghanaian children 9-15 years

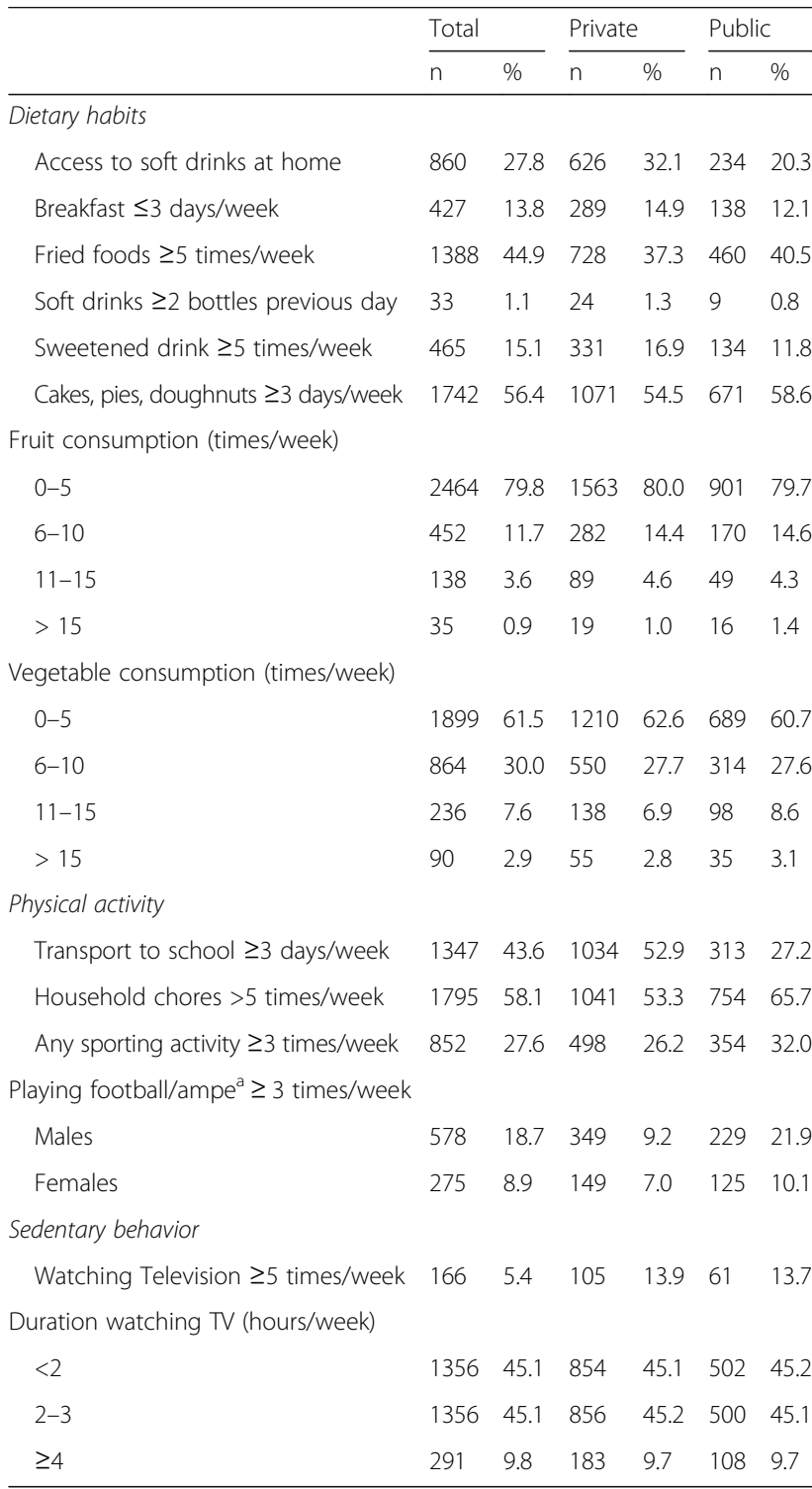

Values presented as number (percentage of private or public)

${ }^{\mathrm{a}} \mathrm{A}$ local game involving clapping and jumping

Table 3 Nutritional status of Ghanaian School children ages 9-15 years

\begin{tabular}{|c|c|c|c|c|c|c|}
\hline \multirow[t]{2}{*}{ Growth status } & \multicolumn{2}{|l|}{ Total } & \multicolumn{2}{|c|}{ Private } & \multicolumn{2}{|c|}{ Public } \\
\hline & $n$ & $\%$ & $n$ & $\%$ & $\mathrm{n}$ & $\%$ \\
\hline Thin & 102 & 3.3 & 55 & 2.9 & 47 & 4.4 \\
\hline Normal & 2429 & 78.6 & 1475 & 75.7 & 954 & 84.3 \\
\hline Overweight & 382 & 12.4 & 282 & 14.2 & 100 & 8.3 \\
\hline Obese & 143 & 4.6 & 113 & 5.8 & 30 & 2.5 \\
\hline Severely obese & 33 & 1.1 & 28 & 1.4 & 5 & 0.4 \\
\hline Stunting & 99 & 3.2 & 50 & 2.6 & 49 & 4.4 \\
\hline
\end{tabular}

Thin: BAZ <-2SD; Overweight: $+1 \mathrm{SD}<\mathrm{BAZ} \leq+2 \mathrm{SD}$; Obese: $+2 \mathrm{SD}<\mathrm{BAZ} \leq+3 \mathrm{SD} ;$ Severely Obese: $B A Z>+3$; Stunting: $H A Z<-2 S D ;(W H O, 2007)$
Table 4 Factors associated with overweight and obesity (BMIZ $>1$ SD) among Ghanaian children 9-15 years

\begin{tabular}{lclc}
\hline & $\begin{array}{l}\text { Adjusted } \\
\text { Odds Ratio }^{b}\end{array}$ & $\begin{array}{l}\text { 95\% Confidence } \\
\text { Interval }\end{array}$ & $p$-value \\
\hline $\begin{array}{l}\text { Child's sex } \\
\text { Female }\end{array}$ & 2.38 & $1.79,3.18$ & $<0.01$ \\
$\begin{array}{l}\text { Male } \\
\text { Breakfast } \geq 3\end{array}$ & 1 & & \\
No days/week & 0.76 & $0.58,1.00$ & 0.05 \\
Yes & 1 & &
\end{tabular}

Eats Cakes, pies, doughnuts $\geq 3$ days/week

$\begin{array}{llll}\text { Yes } & 0.83 & 0.66,1.04 & 0.10\end{array}$

No

Fruit consumption (frequency/week)

$\begin{array}{llll}>15 & 0.41 & 0.14,1.17 & 0.09 \\ 11-15 & 1.13^{\mathrm{a}} & 0.65,1.93 & 0.67 \\ 6-10 & 1.07^{\mathrm{a}} & 0.78,1.46 & 0.69 \\ 0-5 & 1 & & \end{array}$

Vegetable consumption (frequency/week)

$\begin{array}{llll}>15 & 1.27 & 0.69,2.32 & 0.44 \\ 11-15 & 1.48 & 0.99,2.23 & 0.06 \\ 6-10 & 1.16 & 0.92,1.46 & 0.20 \\ 0-5 & 1 & & \end{array}$

Transported to school (days/week)

$\begin{array}{llll}4-5 & 1.39 & 1.06,1.82 & 0.02 \\ 1-3 & 1.11 & 0.52,2.37 & 0.79 \\ \text { Never } & 1 & & \end{array}$

Engaged in any sporting activity $\geq 3$ times/week

$\begin{array}{llll}\text { No } & 1.44 & 1.07,1.94 & 0.02\end{array}$

Yes

1

School type

$\begin{array}{llll}\text { Private } & 1.74 & 1.31,2.32 & <0.01\end{array}$

Public $\quad 1$

Maternal education

$\begin{array}{llll}\text { Tertiary } & 1.91 & 1.07,3.42 & 0.03 \\ \text { Secondary } & 1.00 & 0.57,1.75 & 0.99 \\ \text { Primary } & 1.12 & 0.68,1.84 & 0.65 \\ \text { Don't know } & 1.14 & 0.69,1.89 & 0.61 \\ \text { None } & 1 & & \end{array}$

Household socioeconomic status

$\begin{array}{llll}\text { High } & 1.56 & 1.18,2.06 & <0.01 \\ \text { Medium } & 1.10 & 0.81,1.49 & 0.54 \\ \text { Low } & 1 & & \end{array}$

${ }^{\mathrm{a} B o r d e r l i n e ~ s i g n i f i c a n t ~ v a l u e s ~}(0.05 \leq P<0.08)$

${ }^{b}$ Other variables controlled in the analysis: age, child engaged in household chores, and frequency of sweetened beverage consumption 
$56 \%$ higher odds of being overweight or obese when compared to those from households in the first tertile (lowest SES). After adjusting for biologic factors, dietary and physical activity habits, and SES, those attending private schools were more likely to be overweight or obese compared those who attended public schools $(\mathrm{AOR}=1.74,95 \% \mathrm{CI}: 1.31,2.32)$.

\section{Discussion}

Among Ghanaian school children 9-15 years living in Accra and Kumasi, the prevalence of overweight (including obesity) was $15 \%$. Fundamentally, overweight and obesity reflects positive energy balance; physical inactivity and poor dietary habits are two key modifiable factors that can influence this balance in a population. In the current study, low physical activity participation was associated with overweight and obesity among school-going children in urban Ghana, similar to earlier studies in other developing countries [2, 21, 22]. Both low participation in structured (sports) and unstructured forms of physical activity (e.g., walking to school) were related to overweight and obesity, indicating the need to encourage varied opportunities for physical activity among school-aged children.

In line with the WHO global strategy on diet, physical activity, and health, the Ministry of Health in Ghana recommends that children and adolescents have at least one hour of moderate to vigorous physical activity daily, and that physical education (PE) of not less than $2 \mathrm{~h}$ per week should be included in the school curriculum $[23,24]$. Although PE is part of the basic education curriculum, studies show that the main focus has been on competitive sports [25]. While PE aims to encourage majority of students to participate regularly in physical activities, competitive sports is described as a value-added experience for few students who show the potential for elite performance in specific structured activities. Thus, focusing mainly on competitive sports in school limits opportunity for the majority of children to engage in school-based physical activity.

Parental work habits is known to influence the level of physical activity among children [26]. When parents work mostly away from home, as is commonly observed in urban settings, there is limited time to supervise or engage in recreational activities with their children. Children are thus left on their own to decide the use of the period after school. With the upsurge of video and computer games and television stations, children are likely to engage in sedentary activities that involve spending time in front of a screen, thereby limiting their opportunities for engaging in moderate and vigorous physical activities. An earlier study in the Ga-East district of Ghana reported that obese and overweight school children
(8-18 years) spent more time watching television and playing video games (90 min/day) than engaging in physical activities (50 $\mathrm{min} /$ day) [27]. In the current study, more than half of children spent at least two hours/day watching television in the week prior to the survey.

The positive association between SES and overweight (including obesity) observed in this study is similar to studies in other developing countries [2, 21, 28, 29]. The direction of the association between obesity and SES varies from positive in poorer countries to negative among better-off societies [30]. Households with high SES may have more access to and be able to afford processed, fatty, and/or sugary foods and beverages compared to poorer households. Socio-Economic Status may also predict access to technology (e.g., television, cars, computers, and video games). These technology devices are likely to contribute to a more sedentary lifestyle. In our study, however, SES was associated with overweight and obesity independent of physical activity. Thus, there may be other factors that mediate the observed relationship.

Available studies on the relationship between maternal education and overweight/obesity in children and adolescents are mixed. While some studies found a positive association [28, 31], others have reported a negative $[32,33]$ or no [21] association. In the present study, children whose mothers had received post-secondary education were more likely to be overweight or obese compared to those who had no formal education. High level of maternal education may lead to improved acquisition and use of nutrition knowledge which can translate into good dietary practices [34]. On the other hand, mothers with higher levels of education are likely to earn higher income. The latter has been linked with adverse affects on dietary and/or physical activity habits through the easier accessibility of energy-dense foods and electronic devices that promote sedentary lifestyles. Thus, the relationship between maternal education and overnutrition among children may be modified by other factors and therefore needs further investigations.

Previous studies have established a strong association between diet and risk of overweight in both developed and developing country settings [35-37]. In the current analysis, however, there was no statistically significant association observed between overweight and any of the indicators of dietary behavior. This can be explained by both the inherent imprecision of measuring diet by recall, as well as the detail of dietary analysis reported in the current analysis. It is important, however, that this finding is neither misunderstood nor misrepresented as evidence of the association between overweight and diet. Subsequent analysis of the dietary data will enable better understanding of the links between diet and overweight as well as other biological outcomes examined (including lipid profile). 
One of the strengths of this study was the use of the WHO growth reference for school-aged children and adolescents in the determination of overweight and obesity. Compared to the previous NCHS growth curves [38], the WHO reference curves are closely aligned with Child Growth Standards at five years of age as well as the recommended adult cut-offs for overweight and obesity at 19 years, which is the WHO upper age limit for adolescence [20]. It provides, therefore, an appropriate reference for the age group that participated in the current study. Further, the study included more than one hundred schools that were located throughout the two largest cities in Ghana. The use of random sampling to select the children enhanced our sample as representative of the school-going children in urban settings in Ghana.

The findings of the current study should be interpreted bearing in mind its inherent limitations. First, we recognise the inability of this study to establish causality due to its cross-sectional design. Additionally, although parental BMI has been shown to be a risk factor for overweight and obesity among children and adolescents $[5,32,33,39]$, this could not be controlled for in the regression analyses. This was due to the lack of anthropometric data for more than $20 \%$ of parents who were interviewed by phone. Finally, and importantly, the dietary information was collected using food frequency questionnaire and thus any interpretations from the diet-related analyses should be viewed with this inherent limitation in mind.

\section{Conclusions}

In conclusion, the prevalence of overweight and obesity among school-going children living in urban areas in Ghana was high. This study identified physical activity status, sex of child, maternal education, household SES, and type of school as significant determinants of overweight and obesity in these children. Of these factors, physical activity is the one that can be modified among school-going children. The current physical education curriculum for basic schools in Ghana needs to be reassessed and updated to encourage more children and adolescents to participate regularly in physical activities. Further, there is need to champion the utilization of the PE time for physical activity in schools. This may require placing more emphasis on non-competitive activities. In addition, school children should be encouraged to walk to school as much as possible and this recommendation should be supported by policies that ensure safety on walk routes.

\section{Abbreviations}

AOR: Adjusted Odds Ratio; BMI: Body Mass Index; BMIZ: Body Mass Index Z-Score; Cl: Confidence Interval; GSHS: School-based Student Health Survey; JHS: Junior
High School; PE: Physical education; SD: Standard Deviation; SES: Socio-Economic Status; WHO: World Health Organization

\section{Acknowledgements}

The study team appreciates the cooperation and support of teachers, parents and school children for their patience and time spent in participating in the data collection process. We also appreciate the facilitative role of the School officials as well as research assistants (Mawuli Avedzi, Hussein Mohamed, and Deda Ogum). Seth Adu-Afarwuah is acknowledged for support with data analyses.

\section{Funding}

This work was carried out with the aid of a grant from the International Development Research Centre, Ottawa, Canada (\#104519-017).

\section{Availability of data and materials}

The datasets analysed during the current study are available from the corresponding author on reasonable request. Alternatively, the data may be accessed from figshare.com (https://figshare.com/s/b84228deedcc5cd54f81). However, access to the data will be restricted by an embargo requiring contact with the Investigators due to ongoing analyses, until January 2018, when the embargo will be lifted.

\section{Authors' contributions}

The study was conceived and designed by AL and GSM. HN supervised data collection. All authors contributed to analyses and interpretation of the data. The manuscript was drafted by RA and AL with substantial contributions by all the other authors (GSM, HN, EC and PB). All authors approved manuscripts, and revisions arising from review process.

\section{Ethics approval and consent to participate}

The study was approved by the Ethical Review Boards of McGill University, Canada and the Noguchi Memorial Institute for Medical Research, University of Ghana, Legon. Written informed consent was obtained from all parents whose children participated in the study. In addition, each participating child provided signed assent before the questionnaire was administered.

\section{Consent for publication}

No identifying information of study participants is included in the manuscript. All authors have provided consent for the publication of the manuscript in its current form.

\section{Competing interests}

The authors declare that they have no competing interests.

\section{Publisher's Note}

Springer Nature remains neutral with regard to jurisdictional claims in published maps and institutional affiliations.

\section{Author details}

'School of Public Health, University of Ghana, Box LG 13 Legon, Accra, Ghana. ${ }^{2}$ Department of Nutrition and Food Science, University of Ghana, Box LG 134 Legon, Accra, Ghana. ${ }^{3}$ School of Dietetics and Human Nutrition, McGill University, 21,111 Lakeshore Road, Ste-Anne-de-Bellevue, Montreal, QC H9X 3V9, Canada. ${ }^{4}$ Department of Biochemistry and Biotechnology, Kwame Nkrumah University of Science and Technology, Kumasi, Ghana.

Received: 5 July 2017 Accepted: 20 November 2017

Published online: 04 December 2017

References

1. United Nations Childrens Fund (UNICEF), World Health Organization (WHO), (WB) WBG. Levels And Trends In Child Malnutrition: Key findings of the 2016 edition. New York: UNICEF/WHO/WB; 2016.

2. Gupta N, Goel K, Shah P, Misra A. Childhood obesity in developing Countires: epidemiology, determinants, and prevention. Endocr Rev. 2012;33:48-70.

3. Popkin BM. The nutrition transition and obesity in the developing world. J Nutr. 2001;131:871S-3S

4. Shetty P. Nutrition transition and its health outcomes. Indian J Pediatr. 2013; 80(Suppl 1):S21-7. 
5. Kiranmala N, Das M, Arora N. Determinants of childhood obesity: need for a trans-sectoral convergent approach. Indian J Pediatr. 2013;80(Suppl 1):S38-47.

6. Hill J, Peters J. Environmental contributions to the obesity epidemic. Science. 1998:280:1371-4.

7. Lee MC, Orenstein MR, Richardson MJ. Systematic review of active commuting to school and childrens physical activity and weight. J Phys Act Health. 2008; 5(6):930-49.

8. Faulkner GE, Buliung RN, Flora PK, Fusco C. Active school transport, physical activity levels and body weight of children and youth: a systematic review. Prev Med. 2009:48(1):3-8.

9. Boulos R, Vikre EK, Oppenheimer S, Chang H, Kanarek RB. ObesiTV: how television is influencing the obesity epidemic. Physiol Behav. 2012; 107(1):146-53.

10. Reid Chassiakos YL, Radesky J, Christakis D, Moreno MA, Cross C. COUNCIL ON COMMUNICATIONS AND MEDIA. Children and adolescents and digital media. Pediatrics. 2016;138(5).

11. Buscemi S, Barile A, Maniaci V, Batsis JA, Mattina A, Verga S. Characterization of street food consumption in Palermo: possible effects on health. Nutr J. 2011;10:119-27.

12. Chauliac M, Bricas N, Ategbo E, Amoussa W, Zohoun I. Food outside the home of schoolchildren in Cotonou (Benin). Sante. 1998:8(2):101-8.

13. Dietz W. Health consequences of obesity in youth: childhood predictors of adult disease. Pediatrics. 1998;101:518-25.

14. Strauss R. Childhood obesity and self-esteem. Pediatrics. 2000;105:e15-20.

15. Dietz W, Gortmaker S. Preventing obesity in children and adolescents. Annu Rev Public Health. 2001;22:337-53.

16. Rosenbaum M. Special considerations relative to pediatric obesity. In: de Groot LJ, Chrousos G, Dungan K, Feingold KR, Grossman A, Hershman JM, Koch C, Korbonits M, McLachlan R, new M, et al., editors. Endotext. South Dartmouth (MA): MDText.com, Inc.; 2000.

17. Llewellyn A, Simmonds M, Owen CG, Woolacott N. Childhood obesity as a predictor of morbidity in adulthood: a systematic review and meta-analysis. Obes Rev. 2016;17(1):56-67.

18. WHO: Global School-based Student Health Survey: Ghana Fact Sheet. 2007. http://www.who.int/chp/gshs/2007_Ghana_fact_sheet.pdf?ua=1. Accessed 27 Nov 2017.

19. WHO: Software for assessing growth and development of the world's children. In.: Geneva: WHO. 2007. http://www.who.int/childgrowth/software/ en/. Accessed 27 Nov 2017.

20. de Onis M, Onyango A, Borghi E, Nishida C, Siekmann J. Development of a WHO growth reference for school-aged children and adolescents. Bull World Health Organ. 2007;85:660-7.

21. Laxmaiah A, Nagalla B, Vijayaraghavan K, Nair M. Factors affecting prevalence of overweight among 12- to 17-year-old urban adolescents in Hyderabad, India. Obesity. 2007;15(6):1384-90.

22. Mushtaq MU, Gull S, Mushtaq K, Shahid U, Shad MA, Akram J. Dietary behaviors, physical activity and sedentary lifestyle associated with overweight and obesity, and their socio-demographic correlates, among Pakistani primary school children. Int J Behav Nutr Phys Act. 2011:8:130-43.

23. Ministry of Health: Dietary and physical activity guidelines for Ghana. In. Accra, Ghana; 2010.

24. WHO: School policy framework: implementation of the WHO global strategy ondiet, physical activity and health. In. Geneva, Switzerland; 2008.

25. Ocansey R, Seidu S, Jatong J. Physical education and after-school sport programs in Ghana: The role of public and private structures. In: ChepyatorThomson J, Hsu S-H, editors. Global perspectives on physical education and after-school sports. Lanham, MD: University Press of America; 2013. p. 13-35.

26. Kohl IIIH, Hobbs K. Development of physical activity behaviors among children and adolescents. Pediatrics. 1998;101(549-554)

27. Steiner-Asiedu M, Addo P, Bediako-Amoa B, Fiadjoe F, Anderson A. Lifesyle and nutrition profile of overweight and obese school children in the Ga-east district of Ghana. Asian Journal of Medical Sciences. 2012;4(3):99-102.

28. Ullmann H, Buttenheim AM, Goldman N, Pebley AR, Wong R. Socioeconomic differences in obesity among Mexican adolescents. Int J Pediatr Obes. 2011;6: e373-80.

29. Daboné C, Delisle HF, Receveur O. Poor nutritional status of schoolchildren in urban and peri-urban areas of Ouagadougou (Burkina Faso). Nutr J. 2011; 10(34):1-8.

30. Ntandou G, Delisle H, Agueh V, Fayomi B. Physical activity and socioeconomic status explain rural-urban differences in obesity: a cross-sectional study in Benin (West Africa). Ecology of Food and Nutrition. 2008;47:313-37.
31. Mushtaq MU, Gull S, Shahid U, Shafique MM, Abdullah HM, Shad MA, Siddiqui AM. Family-based factors associated with overweight and obesity among Pakistani primary school children. BMC Pediatr. 2011;11:114-22.

32. Keane $E$, Layte R, Harrington J, Kearney PM, Perry IJ. Measured parental weight status and familial socio-economic status correlates with childhood overweight and obesity at age 9. PLoS One. 2012;7(8)

33. Yi XQ, Yin CY, Chang M, Xiao YF. Prevalence and risk factors of obesity among school-aged children in Xi'an, China. Eur J Pediatr. 2012;171(2):389-94.

34. Armar-Klemesu M, Ruel MT, Maxwell DG, Levin CE, Morris SS: Poor Maternal Schooling is the Main Constraint to Good Child Care Practices in Accra. J Nutr. 2000; 130(6):1597-607.

35. Kuzbicka K, Rachon D. Bad eating habits as the main cause of obesity among children. Pediatric endocrinology, diabetes, and metabolism. 2013;19(3):106-10.

36. Katzmarzyk PT, Broyles ST, Champagne CM, Chaput JP, Fogelholm M, Hu G, Kuriyan R, Kurpad A, Lambert EV, Maia J, et al. Relationship between soft drink consumption and obesity in 9-11 years old children in a multi-National Study. Nutrients. 2016;8(12):E770.

37. Emmett PM, Jones LR. Diet, growth, and obesity development throughout childhood in the Avon longitudinal study of parents and children. Nutr Rev. 2015;73(Suppl 3):175-206.

38. Kuczmarski RJ, Ogden CL, Guo SS, Grummer-Strawn LM, Flegal KM, Mei Z Wei R, Curtin LR, Roche AF, Johnson CL: 2000 CDC growth charts for the United States: methods and development. In., vol. 11: National Center for Health Statistics; 2002

39. Moraeus L, Lissner L, Yngve A, Poortvliet E, Al-Ansari U, Sjoberg A. Multi-level influences on childhood obesity in Sweden: societal factors, parenta determinants and child's lifestyle. Int J Obes. 2012;36(7):969-76.

\section{Submit your next manuscript to BioMed Central and we will help you at every step:}

- We accept pre-submission inquiries

- Our selector tool helps you to find the most relevant journal

- We provide round the clock customer support

- Convenient online submission

- Thorough peer review

- Inclusion in PubMed and all major indexing services

- Maximum visibility for your research

Submit your manuscript at www.biomedcentral.com/submit
) Biomed Central 